\title{
ANALISIS BEBAN PENGGUNA PADA TELETRAFIK INTERNET STTA MENGGUNAKAN SISTEM SHARING
}

\author{
Amanda Cahya Ristia Putri ${ }^{1}$, Yenni Astuti ${ }^{2}$ \\ Program Studi Teknik Elektro \\ Sekolah Tinggi Teknologi Adisutjipto \\ Jalan Janti, Blok-R, Lanud Adisucipto, Yogyakarta, 55198 \\ Email : ${ }^{1}$ rramandacahyaa@yahoo.com.sg, ${ }^{2}$ yenni.stta@gmail.com
}

\begin{abstract}
Internet needs in education has become a basic requirement, whether it is for faculty, students, complementary components of universities such as bureaus, public relations, $T U$, and non-academic staff As the number of Internet users continues to increase, especially in educational institutions, including STTA's, an observation of the STTA Internet network data stream is conducted. A parameter to be observed is user's load, as it affects the quality of services that will be generated by the STTA Internet Network. This research provides an analysis to measure the size of user load as well as to know the amount of loss so that it can be a reference in subsequent research to reduce the amount of loss in order to fit in the good category traffic. Model sharing system is used to describe traffic data both elastic and stream at flow level. Observation results show that the average arrival rate of STTA is $11 \mathrm{kbps}$ with average service rate of $59 \mathrm{kbps}$. This research uses the measured throughput of $86 \mathrm{Mbps}$. Throughput is calculated from the total number of bits of some successful packet arrivals per second via a network system. With the Internet link capacity of $100 \mathrm{Mbps}$ STTA, after the analysis by the method of sharing system, it is seen that the traffic flow loss is 16\%. From this traffic flow loss value, it can be concluded that the STTA's Internet is include in medium category.
\end{abstract}

Keywords : User Load, Internet, Throughput

1. Pendahuluan

Pesatnya pertumbuhan teknologi informasi di era globalisasi sekarang ini memungkinkan kita untuk mendapatkan informasi dengan mudah. Informasi bisa didapat di mana pun dan kapanpun. Sekolah Tinggi Teknologi Adisutjipto (STTA) merupakan salah satu perguruan tinggi swasta yang sedang berkembang di wilayah Yogyakarta. Untuk mengembangkan kampus menjadi lebih baik tentunya fasilitas akses data bagi mahasiswa menjadi salah satu hal untuk menunjang pembelajaran mahasiswa agar dapat mengakses informasi yang bisa didapat dari media Internet.

Trafik data dalam Internet STTA juga semakin berkembang, dalam hal jumlah dan kepadatan. Peningkatan ini akan lebih baik bila diiringi dengan monitoring traffic, khususnya yang berkaitan dengan bidang teletraffic. Tujuannya tentu saja untuk mendapatkan gambaran yang berupa pemodelan, mengenai kondisi jaringan Internet, khususnya aliran data.

Penelitian mengenai rekayasa trafik oleh [1] membahas tentang analisa untuk membuat trafik bisa terukur secara benar pada kualitas pelayanan 
terhadapt kapasitas sistem. Model sharing system yang digunakan sesuai untuk menjelaskan data trafik elastik pada level aliran. Dalam melakukan pengiriman data trafik, dapat dijumpai bermacam-macam trafik dengan sifat yang berbeda, seperti User Data Protocol yang connectionless oriented dan Transmission Control Protocol yang bersifat connection oriented. Penelitian oleh [2], dengan judul Analisis Throughput Trafik Data menggunakan Model Sistem Sharing. Penelitian tersebut membahas penelitian untuk mengamati trafik data di instansi pendidikan, yakni STTA Yogyakarta, menganalisis data tersebut, dan menghitung nilai kualitas layanannya yang dinyatakan dalam bentuk throughput dan loss. Model sistem yang digunakan untuk melakukan analisis adalah model teletrafik sistem berbagi. Hasil penelitian berupa model sistem, langkah analisis, serta nilai throughput dan loss. Nilai throughput dan loss dari penelitian ini, berturut-turut, adalah 93.200.000 bit per detik dan 0,068 persen. Penelitian oleh [3], dengan judul Analisis pengaruh kapasitas kanal terhadap Quality of Service (QoS) varian real time polling service (RTPS) pada WIMAX IEEE 802.16D". Penelitian tersebut membahas tentang menganalisis pengaruh QoS pada layanan live streaming dilihat dengan tiga parameter yaitu delay, throughput, dan packet loss. Penelitian ini dilakukan dengan mengubah besar kapasitas kanal pada BS. Kapasitas kanal akan diubah di service flow. Besar kapasitas kanal pada penelitian ini terdapat 10 variasi yaitu 64 kbps - 6000 kbps. Hasil penelitian menunjukkan delay dengan data simulasi yaitu $>150 \mathrm{~ms}$. Data hasil simulasi sebesar 287,63 ms pada kapasitas kanal $64 \mathrm{kbps}$, nilai tersebut tergolong kategori buruk menurut standar ITU-T G.114. Hasil simulasi untuk throughput relatif stabil dengan semakin besar kapasitas kanal maka throughput juga semakin besar. Packet loss menujukkan hasil fluktuatif dengan semakin besar kapasitas kanal maka packet loss semakin kecil. Hal ini tentunya tergolong kategori baik menurut standar TIPHON.

2. Metode Penelitian

Tahapan dalam penelitian berupa studi literatur, pengumpulan data, pengolahan data menggunakan Matlab R2016a, dan analisis. Penelitian menggunakan data yang bersumber dari database yang berisi data permintaan akses Internet ke Server yang ada di STTA. Proses pengambilan data dilakukan selama 20 hari kerja berturutturut dengan interval waktu 1 jam yaitu dari pukul 10.00 WIB sampai dengan pukul 11.00 WIB. Sampel data pengamatan seperti tertampil pada gambar 1.

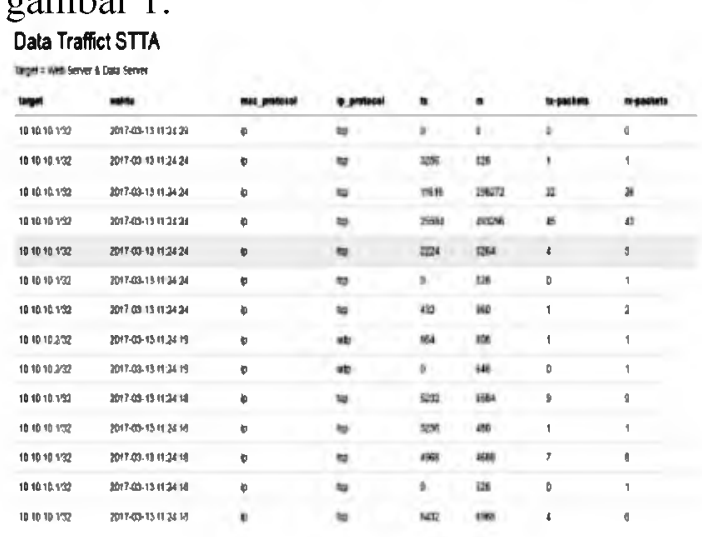

Gambar 1. Sampel data pengamatan.

Data yang didapat berupa berkas database SQL yang selanjutnya dikoneksikan menggunakan ODBC agar dapat terhubung ke Matlab untuk selanjutnya dihitung agar dapat dianalisis sesuai parameter yang diinginkan. Proses analisis menggunakan fitur GUI pada Matlab R2016a, seperti ditampilkan pada Gambar 2. 
Adapun parameter yang digunakan untuk menganalisis dalam penelitian ini adalah Laju Kedatangan, Laju Layanan, Beban Trafik, dan Throughput.

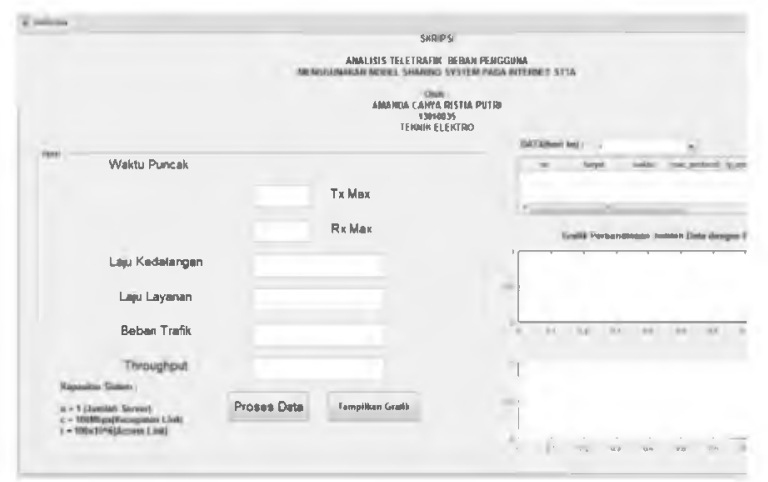

Gambar 2. Tampilan GUI untuk pengolahan data

\section{Hasil dan Pembahasan}

Dari hasil pengamatan laju trafik dan paket data, terlihat bahwa Rx nya lebih besar daripada Tx. Hal ini disebabkan karena $\mathrm{Rx}$ adalah laju data atau jumlah paket yang di kirim dari server ke mikrotik. Sedangkan $\mathrm{Tx}$ adalah laju data atau jumlah paket yang di minta dari mikrotik. Permintaan dari mikrotik merupakan permintaan yang berasal dari berbagai client/pengguna yang mengakses server.

Pengamatan dan pengukuran pada jaringan Internet di STTA yang menggunakan penyambungan paket dan berbasis TCP (Transmission Control Protocol) dan UDP (User Datagram Protocol), telah membuktikan bahwa banyak sekali variasi yang ada. Variasi yang paling dasar adalah pengamatan pada level paket. Artinya trafik elastik yang sedang berada di aliran data Internet diamati sebagai suatu paket yang sedang bergerak. Data yang dipakai dalam penelitian tugas akhir ini adalah data kuantitatif. Dalam tahap analisis digunakan 4 parameter yaitu Laju Kedatangan, Laju Layanan, Beban Trafik, dan Throughput.

\subsection{Laju Kedatangan}

Laju kedatangan biasanya dinotasikan dengan lambda $(\lambda)$ sama dengan tingkat kedatangan rata-rata laju trafik per unit waktu. Jumlah rata-rata laju kedatangan trafik dalam penelitian ini adalah $\lambda=11.444,697 \mathrm{bps}=11$ kbps. Jadi laju kedatangan pelanggan rata-rata $=11 \mathrm{kbps}$

\subsection{Laju Layanan}

Laju pelayanan $\mathrm{Rx}$ rata-rata $(\mu)$ adalah distribusi waktu pelayanan yang dibutuhkan untuk melayani pelanggan. Jumlah rata-rata waktu pelayanan dalam penelitian ini diperoleh nilai $\mu=$ $59.045,056$ bps $=59$ kbps. Jadi laju pelayanan server rata-rata $=59 \mathrm{kbps}$

\subsection{Beban Trafik}

Definisi beban trafik $(\rho)$ adalah perbandingan antara laju kedatangan $(\lambda)$ dengan laju layanan $(\mu)$.

Tx rata-rata $(\lambda)=11.444,69$ bps $=$ $11 \mathrm{kbps}$

$\mathrm{Rx}$ rata-rata $(\mu)=59.045,04$ bps $=$ $59 \mathrm{kbps}$

$$
\begin{aligned}
& \text { Traffic Load }=\frac{\lambda}{n \mu}, \rho= \\
& \frac{11 \times 10^{3}}{1 \times 59 \times 10^{3}}=0,18
\end{aligned}
$$

Besarnya beban trafik yang diperoleh dari penelitian ini adalah 0,18 .

\subsection{Throughput}

Throughput adalah kecepatan (rate) transfer data efektif, yang diukur dalam bit per second (bps). Throughput merupakan jumlah total kedatangan paket yang sukses yang diamati pada destination selama interval waktu tertentu dibagi oleh durasi interval waktu tersebut.

Berdasarkan dari referensi buku Samuli Alto dengan judul buku 
Introduction to Teletraffic Theory (III) 3 ECTS Spring 2007 Bab Sharing System halaman 20, hasil dari perhitungan Probability of waiting (PW) didapatkan nilai sebesar $15,47 \%$.

Untuk mencari nilai throughput menggunakan rumus yang diambil dari Buku Samuli Alto, dengan data yang diketahui sebagai berikut:

$\square$ Tx rata-rata $(\lambda)=11 \mathrm{kbps}$

Rx rata-rata $(\mu)=59 \mathrm{kbps}$

Beban trafik $(\rho)=0,18$

Kecepatan access link untuk aliran $(\mathrm{r})=100 \mathrm{Mbps}=100 \times 10^{6}$ bps

$\square \mathrm{PW}=0,1547$

Rumus Throughput:

$\theta=\frac{\mathrm{E}[\mathrm{L}]}{\mathrm{E}[\mathrm{D}]}=\frac{\mathrm{r} \cdot \mathrm{E}[\mathrm{L}]}{\mathrm{E}[\mathrm{D}]}=\frac{\mathrm{r} \cdot \mathrm{n}(\mathbf{1}-\rho)}{P W+\mathrm{n}(1-\rho)}=$
$\frac{(1-\rho)}{P W+\mathrm{n}(1-\rho)}$

keterangan:

$\mathrm{n} \quad=$ Jumlah server yang dipakai di STTA $=1$

$\rho=$ Beban trafik

$\mathrm{C}=$ Kecepatan saluran yang dipakai di STTA $(100 \mathrm{Mbps}=$ $100 \times 10^{6} \mathrm{bps}$ )

$\mathrm{r} \quad=$ Kecepatan saluran akses untuk aliran (data unit per waktu unit)

$\mathrm{E}[\mathrm{L}]=$ rata-rata flow size (unit data)

$\mathrm{E}[\mathrm{D}]=1 / \mu=\mathrm{E}[\mathrm{L}] / \mathrm{r}=$ rata-rata waktu aliran dengan kecepatan saluran akses.

Throughput diperoleh dengan memasukkan hasil perhitungan (1) dan (2):

$$
\theta=\frac{\mathrm{E}[\mathrm{L}]}{\mathrm{E}[\mathrm{D}]}=\mathrm{r} \cdot \frac{\mathrm{n}(1-\rho)}{P W+\mathrm{n}(1-\rho)}
$$

$\theta=\frac{\mathrm{E}[\mathrm{L}]}{\mathrm{E}[\mathrm{D}]}$

$=100.10^{6} \times \frac{1(1-0,18)}{0,1547+1(1-0,18)}$

$=84 \mathrm{Mbps}$
Pada kapasitas kecepatan saluran sebesar $100 \mathrm{Mbps}$ dengan kondisi saluran yang sibuk, throughput Internet di STTA dengan metode sharing system belum memenuhi kriteria bagus menurut ITU-T berdasarkan tabel 1 dengan kategori aliran loss pada interval $16-25 \%$. Hasil dari throughput yang di dapat 16 Mbps menjelaskan, bahwa nilai tersebut mengalami aliran loss sebesar $=\frac{100 \mathrm{Mbps}-84 \mathrm{Mbps}}{100 \mathrm{Mbps}} \times 100 \%=$ $16 \%$ yang mana masuk dalam kategori sedang.

Tabel 1. Kategori aliran loss

\begin{tabular}{|c|c|c|}
\hline $\begin{array}{c}\text { Kategori Aliran } \\
\text { Loss }\end{array}$ & $\begin{array}{c}\text { Aliran } \\
\text { Loss }\end{array}$ & Indeks \\
\hline Sangat bagus & $0-3 \%$ & 4 \\
\hline Bagus & $4-15 \%$ & 3 \\
\hline Sedang & $16-25 \%$ & 2 \\
\hline Jelek & $<25 \%$ & 1 \\
\hline
\end{tabular}

\section{Kesimpulan dan Saran}

Adapun kesimpulan yang didapat dari hasil penelitian ini adalah :

1. Laju kedatangan pada aliran data trafik setelah dilakukan monitoring memiliki nilai ratarata $11 \mathrm{kpbs}$ dan laju layanan pada aliran data trafik setelah dilakukan monitoring memiliki nilai rata-rata $59 \mathrm{kbps}$.

2. Beban trafik yang terhitung oleh analisis adalah sebesar 0,18 .

3. Throughput pada internet STTA, dengan kapasitas maksimal sebesar $100 \mathrm{Mbps}$, menunjukkan bahwa hasil monitoring maupun perhitungan trafik data di jaringan internet STTA diperoleh nilai $84 \mathrm{Mbps}$. Artinya terjadi loss sebesar 16\%, yang mana menurut kriteria ITU-T masuk dalam interval yang kategori sedang yaitu $16-25 \%$. 
Adapun saran yang didapat dari hasil penelitian ini adalah :

1. Perlu dilakukan adanya penelitian lebih lanjut tentang cara mengontrol aliran paket data jaringan komputer pada internet STTA agar masuk dalam kategori baik.

2. Penelitian dilakukan dengan simulasi untuk melihat apakah sistem yang disarankan bisa mengontrol aliran paket data jaringan komputer sehingga dapat mengurangi jumlah loss.

\section{Ucapan Terima kasih}

Penulis mengucapkan terima kasih kepada P3M STTA yang telah memberi dukungan finansial terhadap penelitian ini.

\section{DAFTAR PUSTAKA}

[1] Prasetya, Agga, 2016, Analisis kapasitas sistem terhadap QoS pada teletrafik internet STTA menggunakan sistem sharing, Skripsi, Jurusan Teknik Elektro, STT Adisutjipto, Yogyakarta.

[2] Astuti, Yenni, 2016, Analisis Throughput Traffic Data Menggunakan Model Sistem Sharing, Jurnal, Program Studi Teknik Elektro, Sekolah Tinggi Teknologi Adisutjipto, Yogyakarta.
[3] Purnomo, Edy Fauzan , 2012, Analisis pengaruh kapasitas kanal terhadap Quality of Service (QoS) varian real time polling service(RTPS) pada WIMAX IEEE 802.16D, Jurnal, Jurusan Teknik Elektro, Universitas Brawijaya, Malang.

[4] Haryadi, Sigit, 2012, Rekayasa Trafik Telekomunikasi, Program Studi Teknik Telekomunikasi, Institut Teknologi Bandung, Bandung.

[5] Mathworks, 2013, Sort Columns by Maximum Value, https://www.mathworks.com/matlab central/answers/110025-sortcolumns-by-maximum-value. Diakses pada tanggal 25 April 2016

[6] Netlab, 2007, Introduction to Teletraffic Theory, Online, http://www.netlab.tkk.fi/opetus/s381 145/k07/lectures.html. Diakses pada tanggal 28 September 2015, pukul 20.51 WIB.

[7] Pratama, I Putu Agus Eka, 2014, Handbook Jaringan Komputer, Informatika Bandung, Bandung.

[8] Samuli, Alto, 2007, Introduction to Teletraffic Theory, online http://www.netlab.tkk.fi/opetus/s381 145/k07/lectures.shtml., diakses 28 September 2016. 